\title{
Dialogue between cultures: FL textbook as a foundation for high-quality education
}

\author{
Irina Pirozhkova* \\ Ural State University of Economics, 620144, 8 Marta Str., 62, Ekaterinburg, Russia
}

\begin{abstract}
High-quality education is one of the main goals of Russia today. To reach it, the educational authorities, textbook and study guides authors and teachers should cooperate to identify the main problems and find their solution. One of the serious challenges of the Russian students is poor knowledge of foreign languages that reduces their chances to continue their education abroad. One of the ways to improve knowledge of a foreign language is to provide motivational and up-to-date educational resources including textbooks and visual aids. This research analyzes ESL textbooks from the point of view of Russia's image presentation. Several cognitive strategies of the country's image presentation have been singled out, among the most frequent are inclusion of phenomena of Russian culture along with culture-bound information of other countries; stereotypical representation of Russian culture without modern socio-cultural context; emphasis on Russian scientific achievements; presentation of traditional and historic facts; and emphasis on Russian politics. Students' attitudes to culture bound materials are revealed in a survey. Recommendations to textbook authors and teachers are provided.
\end{abstract}

\section{Introduction}

Integration of Russia in the international community has affected the educational system of the country. This integration has been accompanied by several activities, firstly, implementation of the Bologna process in 2003 which requires transformation of the higher education system, secondly, modification of requirements to a graduate which include not only professional skills, but also soft skills in different areas, for example knowledge of a foreign language, and finally emphasis on the importance of learning English in Russia, as it is the language of politics, science, economics, business, tourism and international communication. Expansion of international cooperation requires improvement of the knowledge of the English language, it is important to be able to talk not only about the everyday topics, but also to communicate in the professional sphere and to express the views on some burning issues of science, economics or business. Thus, the educational system in Russia faces an important problem of language proficiency improvement to make Russian students and future professionals more competitive in the international labor market.

Today there is a variety of resources to teach and learn a foreign language: podcasts and videos (youtube, BBC learning English), online platforms and apps (British council, duolingo, livemocha, etc.), game-based learning platforms (quizlet, memrise, kahoot, 
mentimeter), apps to communicate with native speakers or robots (italky, skype, hellotalk) and others. However, the central element of teaching a foreign language in most schools and universities is still a textbook or teaching and methodological complex (the term is frequently used in the Russian educational system to describe a set of teaching aids that includes a textbook, a workbook, a teacher's book, tests, audio and video files and some other resources). There is no doubt that students are influenced by the textbook materials which can shape their worldview, attitudes and develop creative thinking. We agree that a textbook "plays a crucial role in shaping cultural and social attitudes and molding the behaviour of the learners" [1].

\section{Research methodology}

\subsection{Methods and materials}

The goal of this study is to examine the content of English as a second language textbooks (further-ESL textbooks) to single out materials referring to the Russian culture in order to identify the most frequent cognitive strategies of Russia's image presentation and to find out students' attitude to culture representation in foreign language textbooks (further - FL textbooks). To reach the goal we used the following methods: interpretation, continuous sampling method, content-analysis, contextual analysis, classification, pedagogical observation, linguodidactic experiment and comparison of results. Material for this research is a number of ESL textbooks popular among Russian teachers and learners, including Challenges, Face2Face, New Headway, Cutting Edge, English File and New Opportunities. In total, 45 textbooks have been examined. We singled out 43 contexts that include information about Russia or the Russians (both verbal and non-verbal). Besides, a survey among students of two Russian universities has been carried out to reveal their attitude to the socio-cultural component in FL textbooks.

\subsection{FL textbooks analysis}

One of the important tasks of linguists, teachers and methodologist today is to create up-todate FL textbooks. Analysis of ESL textbooks from different perspectives may help to identify the main principles of up-to-date learning materials design. In this research we have studied foreign papers on the problems of FL textbooks published in 2019-2020 in different scientific journals indexed in the Web of Science database. This analysis revealed that there are five main areas in the focus of researchers' attention: 1) discussion of the role of socio-cultural material in a FL textbook, 2) description and classification of non-verbal elements of a textbook, 3) analysis of textbook vocabulary, 4) examination of types of exercises and 5) identification and discussion of the role of gender component in a FL textbook. The first two approaches are relevant for this study. We agree that "textbooks used in foreign language instruction cannot be simply separated from cultural contexts because the mere study of the abstract system of language does not equip learners with the required knowledge, skill, and attitudes to interact effectively and meaningfully in real situations" [2]. In some ESL textbooks there is a certain misbalance in culture representation with the dominance of the English-speaking phenomena, while foreign culture is rather stereotypical and shallow [3]. Emphasis on the native culture of learners might benefit their integration in the society of the native speakers and provide a multifaceted image of not only English speaking world, but also show its connection with the other languages and cultures [4]. Some English textbooks present the so-called "interactional culture" that is a synthesis of the source culture (that of the English-speaking 
world) and some other cultures [5]. The cultural component becomes the main in the content of international English textbooks (for instance, English File) and the aim of teaching has shifted in them from communicative competence development to the intercultural competence formation [6]. Many contemporary textbooks show a tendency of multiculturalism that reveals itself in the use of iconic images connected with different cultures [7]. Some ESL textbooks, however, still ignore the target culture completely, which gives rise to serious academic problems [8].

Another popular approach to FL textbooks analysis is the study of non-verbal elements representation. This problem is closely connected with intercultural competence development described above, as images are often analyzed from the point of view of culture representation. For example, it is examined how pictures and photos communicate knowledge about the world and what role they play to establish relations between the textbook author and students. "Critical textbook analysis should attempt to demonstrate the ideological nature of meaning-making by examining the interplay of multimodal representations, the interactive meaning of textbooks' multimodal material as well as the pedagogic-didactic frame within which learners encounter them" [9]. Images may become an effective tool to bridge different cultures with the English-speaking world, but "the critical multimodal content analysis of textbook characters and their interactions suggests that a general western bias and implicit support of native-speakerism are still existent in Korean EFL textbooks" [10].

So, multicultural competence becomes the leading one in FL teaching and its successful development is possible only if the source culture, the international culture and the target culture are presented in a well-balanced way.

\subsection{Sample and procedure}

During this research we made a survey among Russian and Chinese students studying in Russia to find out if they are satisfied with their FL textbooks. The hypothesis of this research is that FL textbooks present the image of the learners' native culture in a simplified and stereotypical way and high-quality language teaching requires adaptation of educational resources to the needs of learners.

Sample: 58 Russian students of the Department of Management and IT of the Ural State University of Economics and 45 Chinese students of the Ural State Pedagogical University took part in the survey. These students are motivated to either continue their education abroad or to work in international companies and they need high level of a foreign language. By a foreign language in this case we mean English for the Russian students and Russian for the Chinese students. The questionnaire contained five main questions for the students to assess their FL textbooks from the point of view of socio-cultural component. Students' answers are shown in Table 1.

Table 1. Role of culture-bound materials in FL textbook (students' view)

\begin{tabular}{|c|c|c|}
\hline \multicolumn{3}{|c|}{ Are there any culture-bound texts, photos and other materials in your FL textbooks } \\
\hline Yes $-75 \%$ & No $-10 \%$ & Didn’t notice $-5 \%$ \\
\hline \multicolumn{3}{|c|}{ What countries did you learn about from FL textbooks? (Russian students' answers) } \\
\hline English-speaking countries $-67 \%$ & Russia $-0 \%$ & Other countries $-33 \%$ \\
\hline \multicolumn{3}{|c|}{ What countries did you learn about from FL textbooks? (Chinese students' answers) } \\
\hline Russia $-85 \%$ & China $-5 \%$ & Other countries $-10 \%$ \\
\hline \multicolumn{3}{|c|}{ Is it useful to learn about different countries (traditions, achievements, people, etc.)? } \\
\hline Yes $-37 \%$ & No $-35 \%$ & I don’t know $-28 \%$ \\
\hline \multicolumn{3}{|c|}{$\begin{array}{l}\text { Would you like to learn about your native country (traditions, achievements, people, } \\
\text { etc.) in the foreign language? }\end{array}$} \\
\hline Yes $-85 \%$ & No $-15 \%$ & \\
\hline
\end{tabular}


Continuation of Table 1

5. Would culture-bound materials (particularly about your native country) in the FL textbook increase your motivation to learn the language?

\begin{tabular}{l|l}
\hline Yes $-87 \%$ & No $-13 \%$
\end{tabular}

So, the survey confirmed that socio-cultural information should be included in a FL textbook in a well-balanced way: it is necessary to tell students about the source culture, but at the same time, the target culture or the native culture of learners must not be neglected. Students who took part in the survey named the following disadvantages of FL textbooks: outdated materials, useless information, general facts that are not interesting to discuss, topics are not connected with their lives, lack of pictures, stereotypes about the native country, etc. To find evidence of the abovementioned, it is necessary to single out the main strategies of Russia's image presentation in ESL textbooks that are frequently used in teaching English in Russia.

\section{Results and discussion}

During the content analysis of ESL textbooks we have found nine cognitive strategies of Russia's image presentation (from the most frequent to the least frequent):

1)Inclusion of phenomena of Russian culture along with culture-bound information about other countries is the most frequent cognitive strategy. It is often found in the sections devoted to nationalities, capitals and flags. Facts about Russia are included in general knowledge quizzes, for instance, "When was the Russian Revolution" (New Headway Elementary 2014, p.54), "Did Leo Tolstoy write War and Peace?" (New Headway Pre-Intermediate 2019, p.45), "Alisher Usmanov is a businessman, where is he from?" (Cutting Edge Starter 2013, p.19). In some cases, Russia and its realia are used to illustrate grammar rules, for instance, the verb "to be" is exemplified by the sentence "I' $m$ from Russia. You're not from Australia. I am not from Italy» (Cutting Edge Starter 2013, p.15). Apart from short and fragmentary contexts, textbooks include longer texts with references to Russia. For example, Cutting Edge Pre-Intermediate (p. 55) tells about travelling in different countries (motorcycle tour round New Zealand, canoeing down the Amazon river): "A train journey to remember! Moscow to Beijing by train - thirteen days and 6000 kilometers across Russia, Siberia and Mongolia...". Sport is quite a popular topic to include facts about Russia: "Russian women tennis players are very popular. Good examples are Maria Sharapova (Wimbledon champion at seventeen) and Svetlana Kuznetsova (US Open champion at nineteen)..."(Challenges 1 2010, p. 24).

Most of the contexts are neutral, they do not have any negative connotations and they simply emphasize the fact that the role of Russia on the international arena is quite big. This strategy represents the multicultural nature of ESL textbooks.

2) Stereotypical representation of Russian culture without modern socio-cultural context is still frequent in contemporary ESL textbooks. Among the most common stereotypes are cold weather in Russia, superstition of the Russians, heavy drinking, and espionage. These are several examples "When I was working in Russia, and I was going to see some friends who lived in the outskirts of the town ... it was very, very cold, it might have been minus $30 \ldots$ at some of the tram stops there were bonfires lit - special street fires to keep people warm..." (New Headway Upper-Intermediate 2014, p. 68). The fact that it is cold in winter arouses no contradiction, but we never lit bonfires at the tram stops nowadays as this habit is a thing of the past, when special bonfires at tram stops were used to heat stones to be put in trams to make tram drivers warm. However the textbook presents this fact as if it is still true. Russian customs and traditions are presented in the following way: "In Russia, for example, you should never shake hands in a doorway... Also avoid leaving empty bottles on 
the dinner table in Russia - that's bad luck" (Face2Face Pre-Intermediate 2013, p.66-67). In our opinion, these are rather superstitions, which do not deserve any attention in an ESL textbook.

On the one hand, stereotypes about Russia are still popular abroad. Such popularity might be promoted by textbooks as well. On the other hand, we did not find any negative stereotypes about Russia, which are still in abundance in Chinese textbooks of the Russian language [11].

3) Emphasis on Russian scientific and technological achievements is a popular strategy in ESL textbooks: "Space agencies in the United States, Russia, Japan, Canada and Europe are working together" (New Headway Elementary 2014, p.82-83); "The first manmade satellite to orbit Earth, Sputnik 1, was launched in 1957/ 1967/1977 by the Soviet Union" (Cutting Edge Intermediate 2013, p.104). So, the country is shown from the positive perspective, as an innovator in various spheres, such as space industry, medicine, television, biology, etc. Thus, contemporary ESL textbooks have a tendency to underline the role of Russian science in the world's technological progress. The textbooks do not include any negative information connected with the military activities of Russia, which are often speculated about in the news.

4) Presentation of traditional and historic facts is less frequent but is still found in several contexts. For example, there are tasks to find the information about different people, places and historical events and traditions, among which indigenous people of Greenland, Canada, the USA and Russia (Cutting Edge Elementary 2013, p.14), unsung heroes like "Mary Seacole - the Jamaican woman who nursed soldiers during the Crimean war and Vasily Alexandrovich Arkhipov - the Russian man who prevented nuclear war". (Cutting Edge Upper-Intermediate 2013, p.65), "Cossack dances are from Russia and Ukraine. They are very energetic - some are more like gymnastics than dancing...” (Challenges 22010 , p.74). Examples of this strategy are not numerous, probably because of poor knowledge of the real Russian traditions and history by the textbook authors and replacement of traditions by stereotypes.

5) Emphasis on Russian politics is often found in ESL textbooks. Among the turning points in history we may find the Great October revolution, the story about which is accompanied by the picture of V.Lenin and a revolutionary slogan in Russian (New Headway Advanced 2019, p. 97), the picture of V. Putin is found among other famous people from different countries - musicians, actors, sportsmen and singers (Cutting Edge Starter 2013, p.17). Lenin's quote is included in one of the exercises: "A lie told often enough becomes the truth" (Face2Face Pre-Intermediate 2013, p.47). In spite of the fact that there are many famous Russian actors, singers, sportsmen, etc. textbooks often prefer to mention political life of Russia as it attracts much attention of the Western world..

The other strategies: 6) reference to the Russian language, 7) presentation of general and superficial knowledge of Russia, and 8) underestimation of the role of Russia on the international arena are much less frequent and they are represented by few examples. For instance, we can find some Russian words: "Privet" (Cutting Edge Elementary 2013, p.8), "sobachka" - the word for @ symbol (New Headway Upper-Intermediate 2014, p.91), pictures of the Red Square (New Headway Elementary 2014, p.57), etc. As for the strategy of exclusion of Russian culture from the textbook materials it is found in two textbooks (Challenges 3 и New Headway Intermediate) which do not mention Russia at all.

\section{Conclusions}

After the survey the following conclusions can be made: 1) students, both Russian and Chinese, understand the importance of socio-cultural information in FL textbooks; 2) Russian students learning English as a foreign language admit that there are a lot of texts 
about the English-speaking countries in their textbooks, while they do not remember any information about Russia in them; Chinese students learning Russian as a foreign language underline the dominance of Russian culture in the textbooks with little attention paid to their native country; 3) culture-bound information in FL textbooks has become quite trivial, it does not arouse much interest of modern students: this information has nothing to do with their lives, they will never go to most of these countries and facts about them are not interesting, they know most of these facts already, the information is outdated - these are popular answers of students; 4) the majority of respondents want to be able to tell about their own country in a foreign language, so FL textbooks should present more "target culture" information; 5) motivation to learn a foreign language might be increased if the native culture of students were paid more attention in FL textbooks. The following reasons for the native culture inclusion were identified by the students: "Knowledge of the native country is important, I can tell my foreign colleagues about Russia/China", "I will understand the history better", "It is easier to learn new grammar/words/other rules on the basis of facts that are close to us", "This information will be useful for my future profession" (this answer was given by the Chinese students, as they want to be tourist guides and interpreters).

Textbooks analysis disclosed the problem of poor representation of the learners' native culture. There are many ESL textbooks and teachers are free to choose the ones to be used in class. Although many universities publish their own textbooks, some materials from popular foreign textbooks are used in class as additional resources. We argue that one of the important requirements to a FL textbook is its socio-cultural content that should include true and relevant facts about the native culture of learners presenting a multifaceted image of the native country without distortion and misinterpretations. Otherwise, FL textbooks do not stimulate dialogue between cultures, they are rather monologues of the Englishspeaking world. So, FL teaching is impossible without teaching culture, as M.G. Bennet wrote «the person who learns language without learning culture risks becoming a fluent fool» [Bennett 2003: 237].

\section{References}

1. H. Ahmad, S.R. Shah, VFAST Trans. on Ed.and Soc.Sc., 5 (2014)

2. M. Amerian, A.Tajabadi, Intercult. Ed. (2020)

3. R. Xiang, V. Yenika-Agbaw J. of Multiling. Multicult. Dev. (2019)

4. H. Motschenbacher_Int. J. of App. Ling., 29. 3 (2019)

5. N.T. Nhan, S. Yutdhana_Pertanika J. of Soc. Sc., 27. 3 (2019)

6. A.L. Espinar, A.R. Rodriguez, Lfe-revista de lenguas para fines especificos. 25. 2 (2019)

7. D. Rojas-Plata LIT. J. of Lang., Lit. and Cult. St., 30. 1 (2020)

8. S. Ahmad, K Yasmin Dil. Cont.-ed. Pol. Y Valores, 6 (2019)

9. C. Weninger Lang. Cult. and Curric. (2020)

10. S.J. Joo, A. Chik, E. Djonov Asian Engl., 22. 1 (2020)

11. L.E.Vesnina, I.V. Kirilova Phil. Class, 1. 55 (2019)

12. J. Bennett, M. Bennett, W. Allen, Developing Intercultural Competence in the Language Classroom. (2003) 